\title{
Unbound: Ethics, Law, Sustainability, and the New Space Race
}

\author{
Chris Impey
}

University of Arizona, Tucson, AZ 85721, USA

e-mail: cimpey@arizona.edu

\begin{abstract}
:
We are witnessing a new space race. A half century after the last Moon landing, and after a decade during which the United States could not launch its own astronauts to Earth orbit, there is new energy in the space activity. China has huge ambitions to rival or eclipse America as the major space power, and other countries are developing space programs. However, perhaps the greatest excitement attaches to the entrepreneurs who are trying to create a new business model for space travel based initially on tourism, and eventually, on colonizing the Moon and Mars and harvesting resources from asteroids. This paper presents a snapshot of the new space race and the rich men behind it, and it looks at some of the ethical and legal issues raised by this activity. The methodology is to consider the stated ambitions of the men leading private space companies, compare and contrast the space endeavor with earlier episodes of exploration and transportation innovation, review the regulatory environment for outer space, and consider two divergent scenarios for the future. Opinions are divided on whether commercial space flight is an expensive indulgence or potentially a way to find sustainability solutions for our life on Earth. It is concluded that the new space race can be characterized as unbounded: in ambition, in terms of laws and regulations, and in terms of ethical constraints on the activity.

Keywords: commercial space industry, space law, space ethics, space debris, sustainability.
\end{abstract}

\section{Introduction}

The exploits of billionaires traveling into space have been prominent in the news in the past year. In the United States, space travel seemed to be moribund, with a decade since the Space Shuttle was retired and nearly fifty years since Americans last set foot on the Moon. Spurred by rapid growth in the private space industry, this article looks at space exploration through the lens of ethics and the law. The research question framed is: What are the legal and ethical bounds on future exploration? To study this 
question, the methodology first involves judging the words of the space pioneers themselves. Then a series of analogies are made between space travel, civil aviation, the Internet, and earlier episodes of human exploration. The limitations imposed by the laws of physics are then considered. Next, the nascent fields of space ethics and space law are reviewed, with the problem posed by space debris and the opportunity afforded by ownership of space resources used as examples. Finally, to highlight the bifurcation of possibilities, two future scenarios are outlined. In the utopian version, space exploration and moving off-Earth are ways to increase the sustainability of human existence. In the dystopian version, a thought experiment reveals the degree to which the regulatory, ethical, and legal framework of space exploration is unbounded. The conclusion is that a fascinating cultural and sociological experiment is currently underway.

\section{Space Boom}

Until recently space travel was difficult, dangerous, expensive, and the exclusive domain of wealthy governments. But private space companies are forging a novel economic model for space travel, based on tourism, recreation, and eventually, the harvesting of resources off-Earth. There are over two dozen space companies with ambitious plans. SpaceX and Blue Origins, companies headed by the two richest people in the world, are leading the charge.

In 2017, for the first time since Sputnik launched the Space Age in 1957, there were more commercial launches into Earth orbit than launches by governments [67]. Over the past decade, the price into Earth orbit has dropped from $\$ 10,000$ per kilo to $\$ 1000$ per kilo. Innovation and competition should drop that to $\$ 100$ per kilo in fifteen years. That would deliver a trip to space for less than the cost of a three-week cruise, opening up space travel to a mass market.

What we are witnessing is analogous to the pioneering era of civil aviation. Back in the 1930's, flying in commercial airplanes was dangerous, expensive, and only for the elite. Now, it is safer than driving, cheap, and easy enough that over 4 billion people flew last year. Space travel is destined to become routine. But the analogy with civil aviation is not perfect. Commercial jets offer a relatively quick way to cross a continent or ocean. Billions of people each year use air travel for business, recreation, and to visit friends and family. Space travel is not about getting from A to B more efficiently. It is about taking people into an alien environment for tourism or pure adventure. There may come a time when spaceships regularly ply routes to the Moon and Mars, but it is decades in the future.

Also, the regulation of spaceflight is playing out differently from civil aviation. Aviation industry leaders knew that government action to improve safety standards was needed for the industry to grow. The Air Commerce Act was passed in 1926, and the Federal Aviation Act in 1958, leading to the formation of the Federal Aviation Administration [11]. Air travel is now amazingly safe, with a fatality rate of three per trillion kilometers traveled. Compare that to car fatalities, which are almost a thousand times higher per kilometer traveled [1]. The U.S. government has kept a light hand on the rudder of the growing commercial space industry. Congress passed a law in 2004 that granted the private sector a "learning period" free of regulation. That period was extended three times and currently expires in October 2023 [16]. There are regulations and safety rules, but people who participate in commercial spaceflight do so through "informed consent," meaning they know they are doing something that could easily kill them. A legal argument has been made that the transfer of liability from commercial space operators to their customers was ill-advised [51].

\section{The New Space Titans}

Who is leading this charge into a zero-gravity future? The most prominent are two idiosyncratic billionaires who, even before they became space titans, have left their mark on the modern world. They 
are men of unbounded ambition. To give an unfiltered view of their aspirations in space, this section quotes them directly.

Even allowing for hyperbole and his thirst for media attention, Elon Musk is one of the most eccentric and dynamic people in the world of business. He was born in South Africa, and after getting degrees in physics and economics, he dropped out of graduate school at Stanford after two days to launch an Internet startup. He joined the board of Tesla in 2004, and has steered that company from a minnow, with sales of 2,500 cars in 2008, to the world's largest electric car company, with over a million sold by 2020 [20]. Tesla's success has played a big part in nudging traditional car builders to make electric vehicles and so advance us towards a future based on renewable energy.

Musk founded SpaceX in 2002, using \$100 million of his early fortune, and he is the CEO and Chief Engineer of the privately traded company. SpaceX started with three failed launches, but since then has racked up an impressive series of achievements. They were the first private company to reach orbit with a liquid-fueled rocket, place a commercial satellite in orbit, reuse an orbital rocket's first stage, put a spacecraft into a heliocentric orbit, send humans into orbit, and send humans to the International Space Station [35]. Their overall success rate for launches and landing the reusable boosters is above 95\%. Although it happened before he was born, Musk was inspired by the Apollo Moon landings: "What actually inspired me to create SpaceX was, I kept expecting that we would continue beyond Apollo 11, that we would have a base on the moon, that we would be sending people to Mars. And that by 2019 probably would be sending people to the moons of Jupiter. And I think actually if you ask most people in 1969, they would have expected that" [39]. Musk was discouraged as he watched NASA founder with the loss of two shuttles and dependence on expensive, expendable rockets. He tried to buy cast-off ICBMs from Russia, but they gouged him on the price. In despair, he decided to go it alone: "I gotta try building a rocket company. I thought this was like almost certain to fail. In fact, I would not let anyone invest in the company in the beginning 'cause it was like, I can't take people's money. This is gonna fail. So I actually funded the whole company in the beginning myself. Not because I thought it would turn out well, but because I thought it would fail" [43].

He did not fail. In 2020, SpaceX sent astronauts to the International Space Station, the first to get there from American soil in nearly a decade since the grounding of the Space Shuttle. As icing on the cake, NASA let SpaceX use pad 39A at Kennedy Space Center, the fabled site of almost all the Apollo and Space Shuttle launches. Musk respects history: "I can't believe we get to use this pad. An insane honor" [39].

Jeff Bezos was a high-flyer from his early days as a student, a National Merit Scholar and high school valedictorian, and summa cum laude graduate of Princeton in computer science and electrical engineering. Few others could have foreseen what lay in the future when he started an online bookstore called Amazon in 1994. But Bezos knew from the start that he wanted it to be the "everything" store. He takes a long view in all his endeavors. He sunk \$42 million into a gargantuan clock being built inside a mountain in Texas; the "Clock of the Long Now" is designed to tell time for 10,000 years [19]. Amazon has over a million employees and some stunning financials - a market capitalization of $\$ 1.6$ trillion, and revenues of $\$ 400$ billion-numbers that put the company in the top five in the world. Amazon has the largest market share, and near-monopolistic influence, in selling books, providing cloud computing, and streaming video. The company was the subject of a New York Times article that exposed its hypercompetitive, dog-eat-dog workplace culture [27]. Franklin Foer, who did a deep dive into the corporate culture of Amazon, summed up its profound place in the world of commerce, and the power of Bezos himself, this way: "In the end, all that is admirable and fearsome about Amazon converges. Every item can be found on its site, which makes it the greatest shopping experience ever conceived. Every item can be found on its site, which means market power is dangerously concentrated in one company... Bezos' company has become the shared national infrastructure; it shapes the future of the workplace with its robots; it will populate the skies with its drones; its website determines which industries thrive and which fall to the side. His investments in space 
travel may remake the heavens. The incapacity of the political system to ponder the problem of his power, let alone check it, guarantees his Long Now. Bezos is fixated on the distance because he knows it belongs to him" [14].

Bezos sells everything to everyone, but he has always dreamed of space. In his high school valedictorian speech, he conjured up a vision of hotels, amusement parks, and human colonies in orbit. He was inspired by the populist vision of moving into space espoused by Gerard K. O'Neil [46]. He has a geeky obsession with Star Trek in all its incarnations, and he has even made his physical appearance converge with that of his fictional hero, Jean Luc Picard. Bezos founded Blue Origin in 2000, and the company has pursued an incremental approach to orbital flight. Incremental and obsessive; the company motto is Gradatim Ferociter, Latin for "Step by Step, Ferociously." Bezos has kept Blue Origin going by selling a billion dollars of his Amazon equity every year. The company has built a space port in West Texas, and it has 3,500 employees, a third of the SpaceX workforce. Bezos stepped down as CEO of Amazon in 2021 to devote himself more fully to his vision of our off-Earth future.

In the financial stratosphere that Bezos and Musk occupy, fortunes can be gained or lost very quickly. Bezos added $\$ 13$ billion to his fortune in 15 minutes when Amazon beat fourth quarter earnings estimates in 2019, and Musk lost \$14 billion in four days after a sell-off in tech stocks in 2021. As for their rivalry to exploit and explore space, while it might look like Blue Origin is the plodding tortoise and SpaceX is the speedy hare, both companies have radically altered the economics of space travel with their reusable rockets. In July 2021, Richard Branson trumped both Bezos and Musk by being the first to fly his own rocket into space. Bezos followed just over a week later. They were both suborbital flights, so bragging rights for first tech mogul in orbit are still up for grabs.

Bezos and Musk agree on one thing: the key to bringing down the costs of launches to Earth orbit is reusability. The ruinous economics of NASA's space ventures boils down to this inefficiency. Here's Bezos: "Reusability is essential because you can never lower the costs to a sufficient degree if you throw the hardware away. That hardware is just too beautiful. First of all, it's just painful. You get this great feeling when looking at a piece of aerospace-grade hardware. It's so beautiful and so precise. To use it once and throw it away is a kind of crime" [2]. Musk makes the point with an analogy: "It would be as though if, in the old days, ships were not reusable. The cost of an ocean voyage would be tremendous. And you'd need to have a second ship towed behind you just for the return journey. So, you can imagine if airplanes were not reusable. Nobody would fly 'cause each airliner costs a couple hundred million dollars. And people do not wanna pay that for a single journey. So, this is why full and rapid reusability is the holy grail of access to space and is a fundamental step towards it, without which we cannot become a multi-planet species" [39].

Then there is Richard Branson and Virgin Galactic. He is more than an afterthought, but he inevitably finds himself in the wake of the powerful progress being made by SpaceX and Blue Origin. Sir Richard Branson shares some traits with both Elon Musk and Jeff Bezos. The titles of his two autobiographies convey his scurrilous streak: Losing My Virginity and Screw It, Let's Do It [3], [4]. Like Musk, he is self-aggrandizing, with a thirst for publicity. He transformed himself, since he suffered from ADHD and dyslexia and was painfully shy as a child. Branson has made cameo appearances in many TV shows and a couple of films. Like Bezos, he started modestly, with a mail order record company he set up at the age of twenty, only to diversify into a plethora of products. At various times you could purchase Virgin brides and Virgin condoms, and you could drink Virgin vodka and Virgin cola. He said he wept when he had to sell Virgin Records to keep his new airline afloat in 1992. Branson launched his space tourism company, called Virgin Galactic, in 2004. His genius move was hiring Burt Rutan, the premier aircraft designer of the past fifty years [69]. Virgin Galactic has had a bumpy road, with three fatalities on the ground and one in flight, and benchmarks reached long after Branson's predictions. However, the company has taken in nearly $\$ 100$ million in deposits for its 
suborbital flights featuring six minutes of weightlessness, which will cost $\$ 450,000$ Like Musk and Bezos, Branson has invested heavily from his own fortune to ensure its eventual success.

Where does all this entrepreneurial activity leave NASA? It has been argued that the space agency is so risk-averse, and puts such a high value on human life, that is has become incapable of innovating [59]. This is the antithesis of the Elon Musk credo to develop fast and break things. NASA has struggled to replace the Space Shuttle with a new capability to lift heavy payloads into Earth orbit. After limping along for five years, Constellation program was cancelled. Its replacement, the Space Launch System, has cost $\$ 20$ billion so far, and it is costing $\$ 2.5$ billion per year with no crewed launch yet scheduled. Yet, NASA has started to partner with the private sector with a series of multi-billiondollar contracts to resupply the International Space Station. Both sides benefit. Companies like SpaceX get the taxpayers to subsidize their substantial development costs, and the near-geriatric space agency learns to be nimbler [45].

\section{Analogy with the Internet}

If we step back from the churn and tumult of the commercial space race, we can see a historical progression that has four distinct phases. It is useful to make an analogy with a central tool of modern life: the Internet [23, p.76].

The first phase belongs to the visionaries and the pioneers. In 1903, Russian scientist Konstantin Tsiolkovsky wrote a book called Exploration of Outer Space by Means of Rocket Devices that presented the equation at the heart of rocketry and laid out how to use multi-stage rockets fueled by liquid oxygen and liquid hydrogen to reach Earth orbit. In 1926, the American inventor Robert Goddard launched the world's first liquid-fueled rocket. Although it only traveled for 3 seconds and 180 feet over a frozen cabbage field on his Aunt Effie's farm, it was the precursor to the mighty Saturn $\mathrm{V}$ rocket that would carry astronauts to the Moon. The analogous phase of the Internet starts with Claude Shannon's foundational paper on information theory in 1948, and a 1960 paper titled "ManComputer Symbiosis" by J.C.R. Licklider that envisaged a worldwide computing network and data in the cloud at a time when the few computers that existed were the size of a family house [73].

In the second phase, the nascent activity is incubated by the military-industrial complex. At the end of the Second World War, German aerospace engineer Wernher Von Braun surrendered to American troops and his work on the lethal V2 rocket was redirected into development of ballistic missiles for the U.S. Army at the height of the Cold War. NASA was established in 1958 and to his credit, President Eisenhower resisted the entreaties of his generals to make it a military agency. NASA's charter put it under civilian control, with transparent reporting and budgets allocated by Congress. Von Braun became the first Director of the Marshall Space Flight Center, devoting his considerable talents to the Saturn V rocket and the goal of landing on the Moon. The Internet also began with funding from the U.S. military, under the Department of Defense's Advanced Research Projects Agency (ARPA). ARPANET, the first computer network, was launched in 1969. Email is the killer application of the Internet and it developed around the same time. For nearly a decade, these tools were only available to people in the U.S. military and a few universities and research institutes [40].

The third phase sees the activity move firmly into civilian life, primarily for the purposes of research. NASA's budget peaked at 4.5\% of the federal budget in 1967, to achieve the herculean feat of getting to the Moon. Since then, it only briefly exceeded 1\% at the peak of Space Shuttle launches. Recently, it has settled to around $0.5 \%$ of the federal purse [44]. Post-Apollo, NASA focused on the Space Shuttle and the International Space Station. There were 135 Shuttle launches over 30 years, and although it was partly reusable, two Shuttles were lost catastrophically, and it was an extremely expensive conveyance. The military put payloads on several dozen flights, but eventually grew frustrated by the cost and the delays so made their own arrangements to get to orbit. The Space Station does demonstrate our ability to live and work in space; it has been continuously occupied for over 
twenty years. But it has cost over $\$ 150$ billion. Neither facility attracted the level of interest from academic and industrial researchers NASA had hoped for. NASA operates in a political landscape that changes with every election cycle, compromising its ability to do long-term, strategic planning. Similarly with the Internet, government investment aimed at supporting research fueled development in the 1980's. The National Science Foundation funded a series of supercomputer centers and the creation of NSFNET, a high-speed successor to ARPANET. University computer scientists developed rules to allow computers to communicate over a network (TCP/IP) and the naming system that is the Internet's version of a phone book (DNS). Tim Berners-Lee, a physicist at CERN, developed the language to share and read documents over the Internet, and a student at the University of Illinois, Marc Andreessen, invented the first web browser [55].

What happens next? With the Internet, by the early 1990's all the tools were in place for seamlessly sending data-text, images, videos - anywhere in the world and displaying them on personal computers. In 1995, NSFNET was decommissioned and restrictions on the use of the Internet for commercial traffic were removed. What followed was an unprecedented surge in economic activity, as culture, commerce and technology were transformed by the Internet. The Internet accounted for $1 \%$ of the information flowing through telecommunications networks in 1993, and that grew to $97 \%$ in 2007 [18]. With one hiatus after the "dotcom bubble' in 2000, the Internet economy has grown to over $\$ 2$ trillion, and two of the four companies with market capitalization above \$1 trillion do their business on the Internet - Google and Amazon [21]. The space industry is booming too. While not at the level of the Internet economy, it is predicted to triple to $\$ 1.4$ trillion by the end of the decade [58]. The new players are disrupters in a good sense, creating new business models and questioning premises that have underpinned government investments in space travel.

Where the analogy breaks down is in the way technology scales and how that affects the economics. The growth of the Internet has been driven by exponential increases in information technology to deliver data. The most famous example is Moore's Law, the doubling of the number of transistors in an integrated circuit every two years. Another example is the doubling of telecommunication network bandwidth every 18 months. The world's computing ecosystem is growing exponentially, which supports the delivery of ever-increasing amounts of information over the Internet [7].

\section{Tyranny of the Rocket Equation}

By contrast with the Internet, space travel is subject to obdurate and immutable laws of physics. Low Earth orbit is only 250 miles, half a day's drive straight up. How hard could it be? Very hard, as shown by the rocket equation Konstantin Tsiolkovsky derived in 1903, an equation that is the foundation of astronautics. He also proposed multi-stage rockets and the use of liquid hydrogen and liquid oxygen for rocket fuel, even though neither was yet available. Inspired by Jules Verne, he thought colonizing space would lead to the perfection of the human species, saying: "The Earth is the cradle of mankind, but mankind cannot stay in the cradle forever" [49].

At first glance, a rocket seems magical. It shudders on the launch pad, billowing smoke and spewing fire, and slowly, majestically, it rises. It is pushing against the launch pad. But then what? How does it continue to rise, and then accelerate, when there's nothing to push against? Rockets are momentum machines. They force gas from combusted fuel out of the nozzle at as fast a speed as possible, making the rocket move in the opposite direction. Isaac Newton worked out the math for this momentum exchange in 1687, and in 1903, Tsiolkovsky applied it to rockets. Let us hear it explained by someone with first-hand experience, Space Shuttle Chief Engineer Don Pettit: "The rocket equation contains three variables. Given any two of these, the third becomes cast in stone. Hoping, wishing, or tantrums cannot alter this result. Although a momentum balance, these variables can be recast as energies. They are energy expenditure against gravity (change in rocket velocity), the energy available 
in your rocket propellant (exhaust velocity), and the propellant mass fraction (how much of the rocket mass is fuel)" [48].

The problem with getting a rocket into orbit is that it has to accelerate all its fuel from zero velocity on the launch pad. If you want to lift a heavier payload, you need more fuel. But then you have to accelerate that fuel, so you have to add more fuel, but then you have to accelerate that additional fuel, and on and on it goes. The "tyranny" of the rocket equation is that the final velocity of the rocket increases slowly as you add more and more fuel. Multiple motors don't help because they just allow you to burn fuel faster at the same exhaust velocity; you don't need any less fuel. Rockets must burn their fuel at a prodigious rate to create enough exhaust momentum to launch a payload. The Space Shuttle gets through 500,000 gallons of liquid propellant in just eight minutes, 2 million times faster than you burn gas driving around town in your car. Air resistance is another obstacle, particularly at low altitudes, and it is not accounted for in the rocket equation. As a result, rockets end up being mostly fuel, some metal, and a small payload. The gigantic Saturn V rocket that sent astronauts to the Moon was $85 \%$ fuel, $13 \%$ rocket parts, and just $2 \%$ the Moon-bound spacecraft with astronauts inside.

In this context, the gains made by SpaceX with mostly reusable rockets are impressive. The progression from Falcon 1 in 2010 to Falcon Heavy in 2020, lowering the cost from $\$ 10,000$ per kilogram to $\$ 1000$ per kilogram, is a halving of the cost every three years. These companies have achieved many efficiencies, but they are still working within the limitations of rocket physics. They are also limited by the use of chemical energy since rockets work the same way now that they did fifty years ago, by combusting fuel and an oxidizer. Hydrogen burning with oxygen is the most energetic combination available for rockets. Chemistry is unable to give us any more energy. However, getting unbound from the Earth is the hard part. It takes a similar amount of energy to go from Earth orbit to Mars or anywhere else in the Solar System.

\section{The Problem of Space Junk}

We can see the outlines of a shining vision of a new frontier. Routine visits to Earth orbit are within reach. The Moon and Mars beckon. This is just the time when we should take a breath, pause, and consider the ethics of space exploration. We have the technology that can liberate us from the Earth's gravity and enable a new realm of commerce and exploration. Will this activity also be for the benefit of humanity and the planet? The answer to this question remains to be determined, but the legal, ethical, and moral framework for space travel is coming into view.

Here are some of the legitimate criticisms about our ventures off-Earth that should be addressed. Space travel is an expensive side show that we can ill afford given problems on the home planet. The new commercial activity is just billionaires with fancy boy toys driven by their egos. We should spend our energy and money taking better care of the terrestrial environment. Space travel will only ever be for the rich, so it will exacerbate existing inequities. Humans have no right to exploit resources is space. Expanding our footprint beyond Earth will just replay the colonial and acquisitive history of the Western world in a new arena. There is so little law and regulation that applies to space that bad actors and unethical companies will face no constraints on their behavior.

Unfortunately, there is already one example where inattention and sloppy practices are creating headaches for future space explorers. Space junk is orbital debris - the detritus of our activity in space. Chunks of metal that no longer serve a useful purpose include non-functional spacecraft, abandoned launch vehicles, cast-off materials from space missions, and fragmentation debris. There are 23,000 pieces of debris larger than a softball orbiting the Earth, tracked by the Defense Department's space surveillance network [15]. Estimated of smaller sizes are half a million the size of a marble or larger and 100 million a millimeter or larger. The problem is that they are all moving at extremely high speeds, up to $17,500 \mathrm{mph}$, and even a tiny fleck of paint can damage a spacecraft at that speed. In the past, Space Shuttle windows had to be replaced because of damage from paint flecks. It makes for quite 
a mental image - nuts and bolts hurtling through space ten times faster than a bullet. About once a year, astronauts on the International Space Station must huddle in the sheltered central hub of the facility after a warning that debris is in the vicinity [15].

The problem is getting worse. As more satellites and spacecraft are launched and more obsolete hardware accumulates in orbit, the probability of collisions increases. In 2007, the Chinese intentionally destroyed one of their old weather satellites, adding 3,500 bits of large, trackable debris and many more small bits of debris to low Earth orbit. In 2009, a defunct Russian spacecraft slammed into an Iridium satellite, contributing 2,300 new hunks of large space junk and many more small chunks. Commercial space companies like SpaceX are planning to launch tens of thousands of satellites in the next decade to facilitate wireless Internet in parts of the world that currently have no coverage. Even before these plans were announced, it was predicted that large collisions could cause cascading collisions, exponentially increasing the number and density of small pieces, and potentially rendering low Earth orbit completely unusable. This dire scenario has is called the Kessler syndrome [28]. We are facing a slow-motion catastrophe, not like the 2013 movie Gravity, where the opening scene showed low Earth orbit rapidly filling up with debris after a missile strike. Brian Weeden of the Secure World Foundation says: "In the movie Gravity, orbital debris was portrayed as sort of a nuclear chain reaction. The reality is the opposite. it's like climate change, a long, relatively slow accumulation of stuff over decades or longer that results in a really big negative impact down the road" [33]. The problem has an ominous overtone because space is the fifth domain of war, alongside land, sea, air, and cyberspace. World powers are arming themselves to take out each other's satellites, offensively or defensively. It is going to get increasingly difficult for a country to tell why their satellite went down or fell silent. Was it a collision with debris, space "weather," or a hostile action?

There is no international treaty governing space debris. A United Nations committee published voluntary guidelines in 2007. Mitigation strategies do exist, but governments have dragged their feet. Large satellites are now built with mechanisms for de-orbiting, and some are in low enough orbits that drag in the thin upper atmosphere does the job in five to ten years. Technologies under consideration include lasers, nets, magnets, and harpoons. In 2019, the European Space Agency awarded the first contract for space clean-up. However, the mission, called ClearSpace-1, will not launch until 2025. Earth orbit is a new "tragedy of the commons," where we ruin something because we all profit from exploiting it and cannot exclude others from doing the same. We have overgrazed public lands, overfished the oceans, and polluted the atmosphere, and we're in danger of ruining the envelope of space above our heads [30].

\section{Space Ethics}

"If you are expecting space ethics to tell you that space exploration is the greatest thing ever, and that we should plunge ahead at all deliberate speed, then you may be in for a disappointment. You are also in for a disappointment if you are expecting space ethics to validate calls to renounce space exploration and to accept our terrestrial horizons." So wrote James Schwartz and Tony Mulligan, philosophers who specialize in the ethics of space exploration and space policy [54]. How we deal with space debris is a test case, but there will be many decisions to make as we explore the "new frontier." Space is a blank slate. We can write our own future there, and hopefully avoid the mistakes that tarnish the legacy of civilizations on Earth. Over a hundred astronomers co-signed a white paper submitted to the Planetary Science and Astrobiology Decadal Survey, the guiding document for funding research in the 2020's in these two fields. They argued: "It is crucial that the planetary science community, with community input, take the opportunity before un-crewed and crewed exploration of other worlds to think ecologically - and seek to equitably address the consequences of our presence on these other worlds" [65]. The private space companies are moving quickly, so there is some urgency to develop this new

field, as framed by this thoughtful recent commentary: "Space ethics must embrace stewardship of the 
space environment, the human rights of those endeavoring to extend civilization into space, the rule of law, and how the benefits of space can broadly benefit humanity while particularly motivating and rewarding those who risk, dare, invent, and invest" [56].

The field of space ethics is young and still evolving. An early conference on the subject was hosted by UNESCO in 2004 [70]. But it is finally getting scholarly attention [34], and it is clear what its role might be in this "new frontier" [53]. It should identify principles for arriving at rational compromises between the different stakeholders in space. For example, should the Moon and Mars be protected in the same way national parks are, or should companies be able to use their land and resources without constraint [5]? Space ethics is not for or against space exploration. It is a tool for identifying and critiquing assumptions that space advocates and space skeptics often fail to realize they are making. Not only can space ethics help us figure what is worth doing in space, it can help us figure out the best way to do those things. For example, if a goal of space resource exploitation is to improve human well-being, which methods achieve that goal with the least collateral damage to the space environment? The ethical arguments have to anticipate rapidly evolving technologies, since it is clear that space companies and those wanting to travel in space are likely to be early adopters of cutting-edge capabilities soon after they leave the research lab. Complex issues will be raised by the use of artificial intelligence in space [60], and the harsh space environment is likely to spur the use of genetic engineering and methods for human enhancement [63].

Finally, space provides valuable perspective. Until now, activity in space has been dominated by American technocrats with a Western, Caucasian lineage. America's space program has often displayed echoes of the $19^{\text {th }}$ century doctrine of manifest destiny, as seen in the pronouncements of a succession of presidents. John Kennedy talked about sailing on a new sea, Lyndon Johnson of space pioneers bound for a glorious New World, George Bush elder and younger compared space missions to Columbus's voyage and Lewis and Clark's expedition respectively, and Donald Trump referred explicitly to America's manifest destiny in the stars [32]. The rhetoric often has religious overtones [62]. American exceptionalism in space makes many people uneasy because it harks back to the colonial past, with its severe mistreatment of indigenous people and Africans [39]. It would be a failure of the imagination not to use the vast arena of space to imagine a different and better world. As we embark on multi-generational projects in space, we should aspire to represent the whole of humanity, examining a broad spectrum of human cultures and value systems. The practitioners of space ethics are primarily academic philosophers.

For those who question the entire enterprise, space is not purely an expensive indulgence. If the satellites that whirl over our heads were to suddenly disappear, modern life would grind to a halt and there would be an economic catastrophe. We would lose all global communications and media, GPS systems, weather forecasting, and the monitoring of critical resources like crops and water. Retreating fully to the Earth is not an option.

At this early stage of the endeavor, space is a blank canvas on which we are painting our dreams and hopes and aspirations. Strikingly diverse visions are on display. The journalist Adam Mann summed it up in an article on how we might treat other planets: "Space still exists mainly in our imaginations, and we all imagine it differently. At one extreme, there's the apocalyptic vision painted by Elon Musk, who wants to back up civilization on Mars in case of a catastrophe on our world. A more optimistic view comes from the "Star Trek" franchise, which has shown humanity coming together in the spirit of science and exploration to discover strange new worlds" [37].

As for the relevance of these experiments for the rest of us stuck on Earth, the prime directive of space colonists will be the efficient use of resources. Water, air, clothes, building materialseverything must be conserved and recycled. Social cohesion will also be essential to survive in such unforgiving environments. The lessons of the first space colonists could help us live more parsimoniously on Earth. 


\section{Earth Resources and Mining Asteroids}

We are using the resources of the planet at an unsustainable rate. A graphic example of this is "Earth Overshoot Day," the day in the year when human demand for ecological resources exceeds what the planet can regenerate in a year [8]. In 2021, this day was July $29^{\text {th }}$. Put another way, in 2021 we used 1.75 Earth's worth of biological resources. The depletion of hydrocarbon resources - coal, oil, gas - is not necessarily bad if that helps accelerate a shift to renewable energy sources. In addition, crucial ingredients of the modern technological world - metals and rare earth minerals - are being used at a rapid rate [29]. When we use fossil fuels, we are drawing down reserves of formerly living creatures deposited underground over a span of hundreds of millions of years. With heavy elements, we are drawing down resources created in the cores of stars before the Earth formed. Until we can master fusion, heavy elements are also non-renewable.

However, it does not follow that we are about to "fall off a cliff" in accessibility of these vital ingredients of modern life. A Saudi oil minister once said: "The Stone Age did not end for lack of stone, and the Oil Age will end long before we run out of oil" [66]. As the known reserves of any resource are depleted basic laws of supply and demand kick in. Prices will rise and that can cause previously marginal or unknown reserves to be put into production. Substitution and recycling can ease the demand, and technology and lifestyle changes may mean that future society's needs are very different from todays. To take a couple of historical examples, flint was highly prized for arrowheads during the Stone Age, but the mining of flint has since stopped, and salt was very valuable to the Romans, but its importance to the world economy has since declined. Predictions about the exhaustion or peak production of resources have usually been wrong [41].

Another thread of the new space race is asteroid mining. In principle, asteroids offer an almost unlimited supply of metals and minerals that have finite supplies on Earth. So far, we have only taken baby steps to mine asteroids. Three missions have returned samples to Earth. OSIRIS-Rex is bringing back the most material, about 60 grams. The goal of that mission is scientific research, which is just as well, since the net cost of $\$ 19$ billion per kilogram would not make for a good economic model.

Estimates of the value of asteroid resources generate eye-popping numbers. A carefully selected near-Earth asteroid five hundred meters across contains about $\$ 2$ trillion worth of precious metals and $\$ 3$ trillion worth of rare earth minerals [36]. Metals like gold and platinum are central to the electronics industry, and the 17 rare earth elements near the bottom of the periodic table are essential in cell phones, car batteries, TV and computer displays, high powered magnets, and a plethora of industrial and high-tech gadgets [22]. All these heavy, iron-loving elements sunk to the Earth's core during its molten youth over four billion years ago, leaving them rare in the crust. A subsequent hail of asteroids dusted the crust with heavy elements, and those are the deposits we mine today. If we bring asteroid material back to Earth, we will be using technology to augment what nature provided eons ago.

Another type of asteroid contains large amounts of water. There are a thousand water-rich asteroids relatively near the Earth, and the two dozen largest each hold 10,000 Olympic swimming pools worth of water [50]. Water does not have high value on Earth, but it is essential is space to drink, hydrate food, and act as a radiation shield. Water can be split into hydrogen and oxygen, with both contributing to rocket fuel and oxygen being available to breathe. Water is heavy and it costs $\$ 10,000$ to get a kilo into Earth orbit, so harvesting it in space is very attractive.

In 2013, Martin Elvis estimated the number of potential mining targets with current technology. He accounted for the number within reach of today's rockets, the feasibility of mining them, and whether or not they would yield a profit. He calculated that 10 metal-rich asteroids and 18 water-rich asteroids were within our grasp [9]. He guesses that advances made by SpaceX over the past decade will increase those numbers by a factor of ten. The best nearby target is Anteros, a 2-kilometer-wide asteroid named after the Greek god who avenged unrequited love. Anteros approaches within 25 times the Earth-Moon distance and it has an estimated metal and mineral value of a whopping \$5.6 trillion 
[74]. But the most seductive target is Psyche. Named after the Greek goddess of the soul, Psyche is 220 kilometers across and 370 million kilometers away in the asteroid belt. Images from the Hubble Space Telescope show it is made almost purely of metals, with a market value of $\$ 10,00$ quadrillion, or 100,000 times the world's economy [25].

\section{Space Law}

With stakes this high, the issue of ownership is important. Lassoing an asteroid and mining it for gold sounds like the Wild West. Will there be any sheriffs out there?

The foundation of space law is a set of five treaties and five sets of principles developed by the United Nations through their Committee on the Peaceful Uses of Outer Space [72]. After ten years of negotiations, the Outer Space Treaty became the first "constitution" for outer space in 1967. It was ratified by 99 countries and signed by an additional 27 states. It says that space is the "province of mankind," and all nations have the freedom to "use" and "explore" outer space, provided it is done in a way to "benefit all mankind." Some its sweeping and vague terms have never been clearly defined. Specific issues were addressed by three subsequent treaties: a "Rescue Agreement" dealing with the return of astronauts from deep space, a "Liability Convention" to address any damage caused by space objects, and a "Registration Agreement" to keep track of all objects launched into space. The Moon Treaty was finalized in 1979. It declares the Moon as part of the Common Heritage of Mankind, and says that lunar resources should be shared among all nations and those resources are "not subject to national appropriation by claim of sovereignty, by means of use or occupation, or by any other means" [71The treaty covers asteroids as well as the Moon, but it is a dead letter since none of the major spacefaring powers have signed it.

All these laws assume space is a realm dominated by countries, not by companies, let alone by individual billionaires. As space industrializes, it is obvious the law has gaping gaps — we have seen one of them in the problem of space junk. Another is the issue of who has jurisdiction and how enforcement works when crimes are committed off-Earth [24]. The new space race is essentially unbound by legal and statutory frameworks.

While international space law languishes, countries have been acting to protect their interests and those of their citizens. In November 2015, Barack Obama signed the U.S. Commercial Space Launch Competitiveness Act into law. The law recognizes the right of Americans to own any space resources they harvest, and it encourages commercial exploitation of asteroids [42]. In 2020, Donald Trump went further, signing an executive order that said the U.S. does not view space as a "global commons." Luxembourg, a tiny European country with outsized ambitions, has passed legislation allowing firms incorporated there to carry out space mining [68NASA is trying to balance encouraging entrepreneurial activity with being a good global citizen. The agency's plans for private-public partnerships in space exploration, the Artemis Accords, are seen by some as a power play by Western countries to control space commence. Before the accords were signed, NASA Administrator Jim Bridenstein tried to sound reassuring, affirming Article II of the Outer Space Treaty, which prohibits national sovereignty over objects in space: "We also believe that, just like in the ocean, you can extract resources from the ocean. But that doesn't mean you own the ocean. You should be able to extract resources from the Moon. Own the resources but not own the Moon" [17].

Not everyone is assuaged. The privatization of space may end up serving the interests of a small number of space capitalists, rather than benefiting humankind as a whole. An extension of capitalism into space might repeat ills we face on Earth: over-exploitation of precious resources, the power of monopolies, and the corruption of crony capitalism. Consider this critique by two social scientists, who contrast an activity they designate NewSpace with the Old Space mode of operations during the Cold War: "Despite its humanistic, universalizing pretensions, NewSpace does not benefit humankind as 
such but rather a specific set of wealthy entrepreneurs, many of them originating in Silicon Valley, who strategically deploy humanist tropes to engender enthusiasm for their activities [57]."

The thought of space "cowboys" lassoing asteroids and deliberately bringing them near the Earth might make you nervous. NASA's rocket scientists, by contrast, are motivated by redirecting asteroids to protect the Earth from potential devastating impacts. Orbital engineering should not be undertaken lightly, and it should definitely be regulated [47].

\section{Sustainability and Living Off-Earth}

Fewer than 600 people have ever been in Earth orbit, and only twelve have set foot on another world. Eight space tourists spent $\$ 20$ million each for a trip. Will space ever be an experience for other than a privileged few? The trajectory of the commercial space industry suggests that space tourism will "take off" in the next few years and suborbital joy rides will become common for wealthy people. We will eventually colonize the Moon and Mars, and routinely live and work in space. The challenge will be to avoid the vision of dystopic science fiction since The Time Machine by H.G. Wells, where civilization is starkly divided into the haves and the have-nots, a majority who live on the degraded Earth and a small minority who live in luxury off-Earth [75]. This theme was also played out in the 2013 movie Elysium. Although Wells' novel was set in Victorian England, his themes of inequality and class prejudice pervade modern society. Exploration of space will only have true value to our species if it plays a role in solving our chronic problems of sustainability and environmental degradation.

As a sign of the potential hazards that lie ahead, consider this dystopian scenario. A private space company sets up a base on Mars. It is registered in a country with almost no regulatory oversight. The large amount of construction is done by the citizens of countries with poor records on human rights, and the workers are essentially wage slaves, putting in years under difficult conditions to guarantee their passage home to Earth. Everyone on base has signed a non-disclosure agreement and members of the press are not allowed to visit. The operators of the base pay no taxes, and the profits they earn from mining are repatriated off-shore, beyond the view of any government. This thought experiment does not violate any current law or enforceable regulation. However, there is a more positive scenario.

On Earth, sustainability must focus on the city. Cities occupy just 3\% of the land area, but hold $55 \%$ of the world's population, generate $75 \%$ of the world's carbon emission, and use $80 \%$ of the world's energy [10]. Most big cities are sprawling, chaotic labyrinths, choked by traffic and shrouded in smog. There are attempts to retrofit cities with public transit and green technology, supported by the United Nations and the World Bank, but it is an uphill battle. The current exemplar is Copenhagen, which is on track to be the first carbon-neutral capital, in 2025. All public transport is electric, and most trips are taken on bicycles, which greatly outnumber cars. From recycling to roof gardens to efficient heating and cooling, Copenhagen is addressing sustainability on all fronts [61]. During the $20^{\text {th }}$ century, the leading architects Le Corbusier, Frank Lloyd Wright, and Buckminster Fuller designed domed cities, but none were evert built [31]. In the Arabian desert outside Abu Dhabi, the city of Masdar is rising. Intended as a one-square-mile showcase of sustainability for 50,000 people, it is far over its $\$ 20$ billion budget, many years behind schedule, and nearly as empty as a ghost town [12].

These projects are far from being self-contained. A closed ecological system would be a habitat that did not rely on any matter or energy exchange outside the system. Very few experiments like this have been attempted. The Institute of Biophysics in Russia built an underground structure for three people in 1965 and ran the project for eight years. The Biosphere 2 experiment in southern Arizona ran for two years from 1991 to 1993. Eight scientists lived in the soaring glass structure, which contained five miniature habitats: a tropical rainforest, a savannah grassland, a mangrove wetland, a coastal fog desert and an ocean with a coral reef. Biosphere 2 attracted a lot of publicity, not all of it favorable. The project was funded by (yet another) eccentric (near) billionaire, Ed Bass. The team did unorthodox 
training with Aborigines in the Australian outback, and personal dramas colored the interactions of the occupants. Late in the experiment, carbon dioxide levels fluctuated wildly, some insect populations crashed while others turned into plagues, and the scientists were forced to start eating their emergency supplies. It was suspected that one snuck out and smuggled in energy bars [13].

For unforgiving environments like the Moon and Mars, habitats must be sealed and the cost of delivering supplies is prohibitive, so recycling and self-sufficiency are essential. NASA published a book on urban planning in space in 1977 [26]. Currently, a team of architects is working with the European Space Agency on a "Moon Village" concept. It would be an expandable settlement at the rim of the Shackleton Crater near the South Pole, a place with water ice and nearly continuous sunlight. Inflatable domes would be covered by protective shells, constructed by robots and 3D printed using lunar soil. In 2017, an MIT team won the Mars City Design competition. Domes and tree habitats, each housing fifty people, would be connected by a series of tunnels. The team leader elaborated on the forest metaphor for the project: "On Mars, our city will physically and functionally mimic a forest, using local Martian resources such as ice and water, regolith (or soil), and sun to support life. Designing a forest also symbolizes the potential for outward growth as nature spreads across the Martian landscape. Each tree habitat incorporates a branching structural system and an inflated membrane enclosure, anchored by tunneling roots [6].

Closed ecological systems are the key to living off-Earth, but they also they have enormous potential applications at home. If pollution and the destruction of fragile ecosystems continues unchecked, these habitats will be essential for sustaining life on Earth [64]. In the science fiction novel 2312, Kim Stanley Robinson envisions a future where we have inhabited other planets in the Solar System. We turn our attention to the ravaged Earth and restore and "re-wild" the planet by returning species that have been preserved in off-Earth sanctuaries [52].

If we move off-Earth in large numbers, ethical issues will be prominent. Propagating life raises basic questions: "Should we expand all life or only intelligent life? Who gets to leave Earth and who makes that decision? Should we allow the population beyond Earth grow without limit? Are space colonists subject to terrestrial laws or will they make their own laws? Should we alter biology on other worlds to suit our needs, or only seed life on dead planets, or not alter nature off-Earth at all? Should we seed life in other solar systems? How far can we change while still preserving the human species, and life itself? [38]"

\section{Conclusions}

The burgeoning commercial space industry is entering uncharted waters. Statements by the billionaires who are leading the effort to launch humans off-Earth reveal unbridled ambition and a fair amount of hubris. Analogies between the evolution of space travel and the evolution of the Internet are useful up to a point, but the analogy with earlier episodes of human exploration on Earth sounds a cautionary note because of its context of colonialism. The only hard bound on the activities of the space entrepreneurs is imposed by the laws of physics. Space law is still in its infancy, and ethicists are scrambling to develop a framework for thinking about how we should operate off-Earth. The optimistic view holds that living in space will teach us how to operate more parsimoniously on the Earth, but dystopian outcomes are not ruled out. For now, we have to trust that the new actors in the space industry will be bound by ethics as they explore the new frontier.

\section{References}

1. Allianz Global Corporate and Specialty. How Aviation Safety Has Improved, 2021, https://www.agcs.allianz.com/news-and-insights/expert-risk-articles/how-aviation-safety-hasimproved.html. 
2. Boyle, A. Interview: Jeff Bezos Lays Out Blue Origin's Space Vision. Geek Wire, 2016, https://www.geekwire.com/2016/interview-jeff-bezos/.

3. Branson, R. Losing My Virginity: How I've Survived, Had Fun, and Made a Fortune Doing Business My Way, London: Virgin Books, 1999.

4. Branson, R. Screw It, Let's Do It, London: Virgin Books, 2006.

5. Cockell, C. and Horneck, G. A Planetary Park System for Mars. Space Policy 20, 2004, pp. 291295.

6. Colagrossi, M. Urban Planning in Space: 3 Off-World Designs for Future Cities. Big Think, 2020, https://bigthink.com/alchemist-city/urban-planning-in-space.

7. Denning, P.J. and Lewis, T.G. Exponential Laws of Computing Growth. Communications of the Association for Computing Machinery 60, 2017, pp. 54-65.

8. Earth Overshoot Day. Earth Overshoot Days Falls on July 29. Earth Overshoot Day, 2021, https://www.overshootday.org/.

9. Elvis, M. How Many Ore-Bearing Asteroids? Planetary and Space Science 91, 2013, pp. 20-26.

10. European Investment Bank. Urban Development Sector. European Investment Bank, 2021, https://www.eib.org/en/projects/sectors/urban-development/index.htm.

11. Federal Aviation Administration. A Brief History of the FAA, 2017, https://www.faa.gov/about/history/brief_history/.

12. Flint, A. What Abu Dhabi's City of the Future Looks Like Now. Bloomberg City Lab, 2020, https://www.bloomberg.com/news/articles/2020-02-14/the-reality-of-abu-dhabi-s-unfinished-utopia.

13. Flynn, L. Closed Ecological Systems: Can They Save The Future? Money Inc., 2019, https://moneyinc.com/closed-ecological-systems-can-they-save-the-future/.

14. Foer, F. Jeff Bezos' Master Plan. The Atlantic Magazine, 2019, https://www.theatlantic.com/magazine/archive/2019/11/what-jeff-bezos-wants/598363/.

15. Garcia, M. Space Debris and Human Spacecraft. NASA, 2021, https://www.nasa.gov/mission_pages/station/news/orbital_debris.html.

16. Grush, L. Private Space Companies Avoid FAA Oversight Again, With Congress' Blessing. The Verge, 2015, https://www.theverge.com/2015/11/16/9744298/private-space-government-regulationspacex-asteroid-mining.

17. Hall, M. In Space, No One Can Hear You Mine: NASA's Blueprint for Space Mining. Mining Technology, 2021, https://www.mining-technology.com/features/in-space-no-one-can-hear-you-minenasas-blueprint-for-space-mining/.

18. Hilbert, M. and Lopez, P. The World's Technological Capacity to Store, Communicate, and Compute Information. Science 332, 2011, pp. 60-65.

19. Hillis, D., Seaman, R., Allen, S., and Giorgini, J. Time in the 10,000-Year Clock. The Long Now Foundation, 2012, https://longnow.org/essays/time-10000-year-clock/.

20. Holland, M. Tesla Passes 1 Million EV Milestone and Model 3 Become All Time Best Seller. Clean Technica, 2020, https://cleantechnica.com/2020/03/10/tesla-passes-1-million-ev-milestone-andmodel-3-becomes-all-time-best-seller/.

21. Hooton, C. Measuring the U.S. Internet Sector: 2019. Internet Association, 2019, https://internetassociation.org/publications/measuring-us-internet-sector-2019/.

22. Hsu, J. Don't Panic About Rare Earth Elements. Scientific American, 2019, https://www.scientificamerican.com/article/dont-panic-about-rare-earth-elements/.

23. Impey, C.D. Beyond: Our Future in Space, New York: Norton, 2016.

24. Ireland-Piper, D. Star Laws: What Happens if You Commit a Crime in Space? The Conversation, 2019, https://theconversation.com/star-laws-what-happens-if-you-commit-a-crime-in-space-122456.

25. Jamasmie, C. NASA Finds Metal Asteroid Worth More Than the Global Economy. Mining.com, 2020, https://www.mining.com/nasa-finds-rare-metal-asteroid-worth-more-than-global-economy/. 
26. Johnson, R.D. and Holbrow, C. (eds.) Space Settlements: A Design Study. NASA Scientific and Technical Office, $\quad$ SP-413, 1977 , https://archive.org/details/SpaceSettlementsADesignStudy1977/page/n1/mode/2up.

27. Kantor, J. and Streitfeld, D. Inside Amazon: Wrestling Big Ideas in a Bruising Workplace. New York Times, 2015, https://www.nytimes.com/2015/08/16/technology/inside-amazon-wrestling-bigideas-in-a-bruising-workplace.html.

28. Kessler, D.J. The Kessler Syndrome. https://web.archive.org/web/20100527195029/http://webpages.charter.net/dkessler/files/KesSym.html.

29. Klare, M.T. The Race for What's Left, New York: Metropolitan Books, 2012.

30. Kluth, A. Space Junk is our New Tragedy of the Commons. Bloomberg Opinion, 2021, https://www.bloomberg.com/opinion/articles/2021-04-17/space-junk-like-overfishing-and-pollution-isa-global-tragedy-of-the-commons.

31. Kohlstedt, K. Self-Contained Cities: Hyperdense Arcologies of Urban Fantasy and Utopian Fiction. 99 Percent Invisible, 2018, https://99percentinvisible.org/article/self-contained-citieshyperdense-arcologies-urban-fiction-utopian-fantasy/.

32. Koren, M. No One Should Colonize Space. The Atlantic, 2020, https://www.theatlantic.com/science/archive/2020/09/manifest-destiny-trump-spaceexploration/612439/.

33. Kwong, E. Space Junk: How Cluttered is the Final Frontier? National Public Radio, 2020, https://www.npr.org/2020/01/10/795246131/space-junk-how-cluttered-is-the-final-frontier.

34. Langston, S.M. Reimagining Icarus: Ethics, Law, and Policy Considerations for Commercial Human Spaceflight. Into Space: A Journey of How Humans Adapt and Live in Microgravity, Chapter 1, 2018, Intechopen, https://doi.org/10.5772/intechopen.74716.

35. Launch List. SpaceX Info, 2021, https://spacex-info.com/launch-list/.

36. Lewis, J.S. Mining the Sky: Untold Riches from the Asteroids, Comets, and Planets, New York: Basic Books, 1998.

37. Mann, A. Is Mars Ours? The New Yorker, 2021, https://www.newyorker.com/science/elements/ismars-ours.

38. Mautner, M.N. Life-Centered Ethics and the Human Future in Space. Bioethics 23, 2017, pp. 433440.

39. McCormick, T. The Billionaire Space Race Reflects a Colonial Mindset that Fails to Imagine a Different World. The Conversation, 2021, https://theconversation.com/the-billionaire-space-racereflects-a-colonial-mindset-that-fails-to-imagine-a-different-world-165235.

40. McCullough, B. How the Internet Happened: From Netscape to the iPhone, New York: Liveright Publisher, 2018.

41. Meinart, L.D., Robinson, G.R., and Nassar, N.T. Mineral Resources: Reserves, Peak Production and the Future. Resources 6, 2016, pp. 14-28.

42. Molloy, M. Asteroid mining Made Legal After Passing of Historic Space Bill by US. The Telegraph, 2015, https://www.telegraph.co.uk/news/worldnews/northamerica/usa/12019740/Whoowns-space-Asteroid-mining-made-legal-in-US-after-passing-of-2015-space-bill.html.

43. Morgan, D. Extended Transcript: SpaceX CEO Elon Musk on Putting Boots on the Moon and Mars. CBS News, 2019, https://www.cbsnews.com/news/extended-transcript-spacex-ceo-elon-muskon-putting-boots-on-the-moon-and-mars/.

44. NASA. Budget Documents, Strategic Plans and Performance Reports. NASA, 2021, https://www.nasa.gov/news/budget/index.html.

45. NASA. NASA and the Rise of Commercial Space: A Symposium to Examine the Meanings and Contexts of Commercial Space. NASA, 2021, https://www.nasa.gov/centers/marshall/history/nasa-andthe-rise-of-commercial-space.html. 
46. O’Neil, G.K. The High Frontier: Human Colonies in Space, New York: William Morrow and Company, 1977.

47. Ostro, S.J. and Sagan, C. Cosmic Collisions and the Longevity of Non-Spacefaring Galactic Civilizations. Interplanetary Collision Hazards, NASA Jet Propulsion Laboratory, Pasadena, CA, 1998, https://trs.jpl.nasa.gov/bitstream/handle/2014/19498/98-0908.pdf.

48. Pettit, D. The Tyranny of the Rocket Equation. NASA, 2012, https://www.nasa.gov/mission_pages/station/expeditions/expedition30/tryanny.html.

49. Redd, N.T. Konstantin Tsiolkovsky: Russian Father of Rocketry. Space.com, 2013, https://www.space.com/19994-konstantin-tsiolkovsky.html.

50. Redd, N.T. Tons of Water in Asteroids Could Fuel Satellites, Space Exploration. Space.com, 2019, https://www.space.com/water-rich-asteroids-space-exploration-fuel.html.

51. Reed, A. Space, the Final Frontier for Negligence Suits-Why Commercial Space Operators Should be Liable for Personal Injuries to Space Flight Participants. Journal of Air Law and Commerce 84, 2019, pp. 477-505.

52. Robinson, K.S. 2312, London: Orbit Books, 2012.

53. Schwartz, J.S.J. and Mulligan, T (eds.). The Ethics of Space Exploration, New York: Springer, 2016.

54. Schwartz, J.S.J. and Mulligan, T. Space Ethics According to Space Ethicists. The Space Review, 2021, https://www.thespacereview.com/article/4117/1.

55. Science and Media Museum. A Short History of the Internet. Science and Media Museum, 2021, https://www.scienceandmediamuseum.org.uk/objects-and-stories/short-history-internet.

56. Sercel, J. and Kwast, J. To Boldly Go... Responsibly. Politico, 2020, https://www.politico.com/news/2020/11/20/space-ethics-opinion-438526.

57. Shammas, V.L. and Holen, T.B. One Giant Leap for Capitalistkind: Private Enterprise in Outer Space. Humanities and Social Sciences Communications 5, 2019, pp. 10-19.

58. Sheetz, M. Bank of America Expects the Space Industry to Triple to a $\$ 1.4$ Trillion Market Within a Decade. $C N B C, 2020, \mathrm{https}: / / w w w . c n b c . c o m / 2020 / 10 / 02 /$ why-the-space-industry-may-triple-to1point4-trillion-by-2030.html.

59. Simberg, R.E. Safe in Not an Option: Overcoming the Futile Obsession with Getting Everybody Back Alive that is Killing Our Expansion into Space, Jackson, WY: Interglobal Media, 2013.

60. Soroka, L. and Kurkova, K. Artificial Intelligence and Space Technologies: Legal, Ethical, and Technical Issues. Advanced Space Law 3, 2019, pp. 131-139.

61. State of Green, City of Copenhagen, State of Green, 2021, https://stateofgreen.com/en/partners/city-of-copenhagen/.

62. Swanson, G.E. The New Frontier: Religion in America's National Space Rhetoric of the Cold War Era. Religions 11, 2020, pp. 592-610.

63. Szocik, K. et al. Future Space Missions and Human Enhancement: Medical and Ethical Challenges. Futures 133, 2021, 102819.

64. Tamponnet, C. and Savage, C. Closed Ecological Systems. Journal of Biological Education 28, 1994, pp. 167-174.

65. Taveres, F. et al. Ethical Exploration and the Role of Planetary Protection in Disrupting Colonial Practices. A Submission to the Planetary Science and Astrobiology Decadal Survey 2023-2032, 2020, https://arxiv.org/ftp/arxiv/papers/2010/2010.08344.pdf.

66. The Economist. The End of the Oil Age. The Economist, 2003, https://www.economist.com/node/2155717/print.

67. The Economist. The Space Race is Dominated by New Contenders. The Economist, 2018, https://www.economist.com/graphic-detail/2018/10/18/the-space-race-is-dominated-by-new-

contenders. 
68. The Economist. Space Law is Inadequate for the Boom in Human Activity There. The Economist, 2019, https://www.economist.com/international/2019/07/18/space-law-is-inadequate-for-the-boom-inhuman-activity-there.

69. The Editors. A Retrospective of Burt Rutan's High-Performance Art. Air and Space Magazine, 2012, https://www.airspacemag.com/flight-today/design-by-rutan-133347555/?no-ist.

70. UNESCO. Legal and Ethical Framework for Astronauts in Space Sojourns. A Symposium. Paris, France: UNESCO, 2004.

71. United Nations. Agreement Governing the Activities of States on the Moon and other Celestial Bodies. United Nations Office for Outer Space Affairs, 2021, https://www.unoosa.org/oosa/en/ourwork/spacelaw/treaties/moon-agreement.html.

72. United Nations. Space Law Treaties and Principles. United Nations Office for Outer Space Affairs, 2021, https://www.unoosa.org/oosa/en/ourwork/spacelaw/treaties.html.

73. Waldrop, M.M. The Dream Machine: J.C.R. Licklider and the Revolution that Made Computing Personal, New York: Viking, 2001.

74. Webster, L. Asteroid Database and Mining Rankings. Asterank, 2021, http://www.asterank.com/.

75. Wells, H.G. The Time Machine, London: William Heinemann, 1895. 